\title{
Human tumour-associated and tumour-specific antigens: Some concepts in relation to clinical oncology
}

\author{
A. M. NeVille, A. M. MACKAY, J. WESTWOOD, C. TURBER Ville, AND \\ D. J. R. LAURENCE
}

From the Institute of Cancer Research, Royal Cancer Hospital, London

It is now well established that human tumours produce and release a wide variety of different, so-called 'inappropriate' substances collectively referred to as tumour index substances. They comprise three different categories of materials, namely, hormones, eg, the 'ectopic' production of ACTH, ADH etc, isoenzymes, eg, the carcinoplacental alkaline phosphatase or Regan isoenzyme, and 'antigens' which consist of materials without known biological or metabolic activity, whether or not they elicit an immune reaction in the tumour-bearing host. This category of 'antigens' is the subject of extensive oncological investigation at present because of their potential value in providing improved methods of cancer detection, diagnosis, and treatment.

At the outset, all the 'antigens' were considered 'cancer-specific', ie, present in or released by tumours only and absent from the corresponding normal tissues. With the development of more sensitive methods of detection and estimation, many can no longer be considered specific. It is possible, consequently, to subdivide the presently known human tumour 'antigens' into two groups, namely, tumour-associated macromolecules and 'tumourspecific' antigens.

\section{Tumour-associated Macromolecules}

The occurrence of members of this first group is better understood as a consequence of the great sensitivity of radioimmunoassay. They are classified as 'antigens' only in the sense that they are detected by immunological procedures but need not elicit a specific immunological response in the host. Most of them are oncofetal antigens, ie, are found in the normal fetus as well as in a variety of tumours, and also occur in body fluids and in patients with nonneoplastic disease. This phenomenon, considered to be shown by all human and experimental tumours, is called 'retrogenetic expression' (Stonehill and
Bendich, 1970). The persistence of these substances $\vec{\circ}$ in some fetal tissues up to the later stages of fetal ${ }_{-}^{-}$ life may induce immunological tolerance. The $\vec{N}$ presence of immunologically identical material ino some normal adult tissues indicates that their ${ }_{-}^{-}$ presence in abnormal cells is not the result of the re-emergence of a process that has been completely suppressed in normal cells.

Changes in the levels in body fluids, while not specific for cancer, may indicate the presence of a $\vec{e}$ tumour with a degree of certainty related to theot actual level found.

\section{'Tumour-specific' Antigens}

By contrast, the 'tumour-specific' antigens are detected by less sensitive methods than those based $\stackrel{\varrho}{\rightarrow}$ on radioimmunoassay. With the acquisition of more윽 precise immunochemical information in the future, $\frac{\Im}{5}$ it may be found that their production is not limited solely to neoplastic cells. However, at the present time they are generally found only in neoplasticoㅇㅇ tissue and blood from tumour-bearing hosts in:whom they induce antibody and/or cell-mediated 3 . immune reactions. These substances cannot be detected in fetal tissues or normal adult tissue with the presently available techniques.

Whereas the major clinical usefulness of the tumour-associated macromolecules may be in the을. area of tumour detection, the tumour-specific antigens may be of importance in relation to tumouro therapy as well as detection.

\section{Tumour-associated Macromolecules ('Antigens')}

Many oncofetal antigens have now been described $\frac{0}{\Phi}$ in association with human tumours (table I). The fetales? pancreatic antigen described by Banwo Versey, and Hobbs (1974) and the tumour polypeptides of Björklund, Wiklund, Lundström, Ekdahl, Hagbard, 


\begin{tabular}{ll}
\hline Without Known Metabolic Activity & With Metabolic Activity \\
\hline Carcinoembryonic antigen (CEA) & Carcinoplacental alkaline phosphatase \\
Alpha-fetoprotein (AFP) & Placental-type hormones and related products \\
Fetal sulphoglycoprotein antigen (FSA) & \\
$a_{2}$ H-Fetoprotein & \\
$\beta S-F e t o p r o t e i n$ & \\
Leukaemia-associated antigens & \\
$\gamma$-Fetoproteins & \\
Fetal pancreatic antigen &
\end{tabular}

Table I Human tumour-associated macromolecules-oncofetal antigens

Kaỹser, Eklund, and Lüning (1973) have now been added to those initially reviewed by Laurence and Neville (1972) and more recently by several groups of workers (Abelev, 1974; Ruoslahti, Pihko, and Seppälä, 1974; Häkkinen, 1974; Neville and Laurence, 1974; Terry, Henkart, Coligan, and Todd, 1974). Two of them, the carcinoembryonic antigen and alpha-fetoprotein, have been the subjects of much work in recent years and will be discussed in detail as illustrative examples of the concept and, despite their relative non-specificity, of the role of these substances in clinical oncology.

\section{CARCINOEMBRYONIC ANTIGEN (CEA)}

The carcinoembryonic antigen (CEA) was described originally by Gold and Freedman (1965) who considered that it occurred solely in primary and metastatic human colorectal carcinomas and in the alimentary tract, liver, and pancreas of the human fetus between the ages of 2 and 6 months. While the initial radioimmunoassay studies of its occurrence in plasma confirmed this apparent specificity for colorectal and pancreatic tumours (Thomson, Krupey, Freedman, and Gold, 1968), many further investigations have now shown that CEA (or CEA-like material) is present in normal adult tissues as well as in numerous varieties of tumours and the plasma from such patients, and in diverse body fluids including those of normal subjects (see review by Neville and Laurence, 1974).

\section{Chemistry}

Carcinoembryonic antigen from metastaticcolorectal carcinomas is a glycoprotein (molecular weight about 200000 ), the protein content of which is approximately $40 \%$ and the carbohydrate approximately $60 \%$. The protein part of the molecule is rich in asparagine or aspartic acid, glutamine or glutamic acid, serine and threonine, but contains no methionine. While CEA preparations from individual metastazing colorectal carcinomas share homogeneity of most immunological and chemical properties, recent work has drawn attention to the existence of heterogeneity typical of glycoproteins as a class. Not all the heterogeneity can be accounted for on the basis of differences in sialic acid (Krupey, Gold, and Freedman, 1968; Newman, Petras, Hamilton, Hager, and Hansen, 1972; Coligan, Henkart, Todd, and Terry, 1973; Turberville, Darcy, Laurence, Johns, and Neville, 1973; Banjo, Shuster, and Gold, 1974). Differences in amino acid composition of CEA of different origins are minor, suggesting that, as with other sialo-glycoproteins, there is a constant polypeptide portion but variation in the outer parts of the oligosaccharide chains. The finding of identical unique $\mathrm{N}$-terminal amino acid sequences in several CEA preparations (Terry, Henkart, Coligan, and Todd, 1972; Chu, Bhargava, and Harvey, 1974) supports this view.

The protein part is thought to contain a single chain containing six intramolecular disulphide bridges (Thomas, Westwood, and Foster, 1974) whose cleavage leads to a large decrease in immunogenicity as measured by radioimmunoassay. Similar losses occur following degradation with dilute acid (Westwood, Thomas, and Foster, 1974b) or proteolytic enzymes (pepsin, subtilisin).

The carbohydrate part of CEA is probably made up of about 40-50 oligosaccharide units each containing 13-15 monosaccharides, joined to the protein via asparagine- $N$-acetyl-glucosamine linkages and rich in fucose, galactose, and $\mathrm{N}$-acetyl-glucosamine. Mannose and smaller amounts of $N$-acetyl-galactosamine and sialic acid are also found. Removal of about $50 \%$ of the carbohydrate by the Smith degradation procedure does not change the immunogenicity of the material as judged by radioimmunoassay (Westwood, Bessell, Bukhari, Thomas, and Walker, 1974a).

\section{Sources of CEA}

At first, CEA was regarded as being a constituent of the colonic tumour cell glycocalyx ${ }^{1}$ (von Kleist and Burtin, 1969; Gold, Krupey, and Ansari, 1970) More recently, evidence has been presented to suggest

${ }^{1}$ The glycocalyx is a mucopolysaccharide-containing layer on the surface of the cell, external to the cell membrane, demonstrable by electronmicroscopy. 
that it is a secreted product retained transiently by the cell membrane (Denk, Tappeiner, Eckerstorfer, and Halzner, 1972).

Carcinoembryonic antigen or CEA-like materials occur in a wide variety of normal and pathological tissues and body fluids (Khoo, Warner, Lie, and Mackay, 1973; Neville and Laurence, 1974). In several cases, these materials have been shown to be immunologically identical with CEA; however, few chemical comparisons are available. Carcinoembryonic antigen from the serum of a patient with advanced metastatic colonic carcinoma was found to have the same $\mathrm{N}$-terminal amino acid sequence and gel filtration behaviour as CEA extracted from tumours (Terry et al, 1974). In contrast, some of the known CEA-reacting molecules are definitely chemically different from 'authentic colonic CEA' on the basis of their higher molecular weight. These include substances found in the urine of normal persons and bladder cancer patients, in semen and in benign breast cyst fluid (Neville, Nery, Hall, Turberville, and Laurence, 1973; Vandevoorde, Newman, Fresolone, MacDonald, and Hansen, 1973; Fleisher, Oettgen, Breed, Robbins, Pinsky, and Schwartz, 1974; Nery, Barsoum, Bullman, and Neville, 1974a; Nery, James, Barsoum, and Bullman, 1974b; Coombes, Hall, and Neville, 1975). It has also been suggested that CEA isolated from breast carcinomas is different from colonic CEA (Chu, 1974).

\section{Clinical application}

The development of sensitive radioimmunoassays to measure CEA in body fluids has resulted in numerous studies of its clinical oncological value as an immunodiagnostic acid. The specificity originally claimed for gastrointestinal tumours (Thomson $e t$ al, 1968) has not been confirmed. Instead, raised levels have been found in plasma in association with a

\begin{tabular}{ll}
\hline Disorder & $\begin{array}{l}\text { Incidence }(\%) \text { of } \\
\text { Raised Plasma } \\
\text { CEA Levels }\end{array}$ \\
\hline Neoplastic & \\
Carcinoma of: & 73 \\
Colon and rectum & 92 \\
Pancreas & 67 \\
Liver & 72 \\
Bronchus & 52 \\
Breast & \\
Non-neoplastic & 21 \\
Ulcerative colitis and Crohn's disease & 42 \\
Cirrhosis and alcoholic liver disease & 25 \\
Chronic bronchitis and emphysema & 7 \\
Fibroadenosis &
\end{tabular}

Table II Incidence of raised plasma CEA levels in various neoplastic and non-neoplastic disorders ${ }^{1}$

${ }^{1}$ From data compiled by Laurence and Neville (1972). wide variety of histogenetically different tumours, $\frac{\vec{J}}{\square}$ and with numerous inflammatory, regenerative, and other non-neoplastic states (table II). Many studies $\underline{-}$ have shown that raised plasma levels are principally a function of the site and extent of tumour spreados or of the tumour volume (Laurence, Stevens, 0 Bettelheim, Darcy, Leese, Turberville, Alexander,흐 Johns, and Neville, 1972) which, together with the many 'false positive' situations, limit severely its $\underset{\varrho}{\mathbb{\Phi}}$ role for the diagnosis or differential diagnosis of early neoplasia.

\section{Patient surveillance}

At present the greatest clinical value of CEA measure- $\stackrel{\omega}{\omega}$ ment is to facilitate the earlier detection of recurrento요 or metastatic colorectal carcinoma (Mach, Jaeger,is Berthelot, Ruegsegger, Loosli, and Pettarel, $1974 ; \overrightarrow{\dot{a}}$ Mackay, Patel, Carter, Stevens, Laurence, Cooper,and Neville, 1974; Sorokin, Sugarbaker, Zamcheck, $\vec{\circ}$ Pisick, Kupchik, and Moore, 1974; table III). In aN

\begin{tabular}{llll}
\hline Clinical Status & Plasma CEA & No. of Patients \\
\hline Well; no evidence of & Normal & 150 \\
recurrence & Rising $(>40 \mu \mathrm{g} / \mathrm{l})$ & 17 \\
& Unchanged & 17 & 10 \\
Recurrence & Synchronous ${ }^{2}$ rise to & 26 & \\
& $>40 \mu \mathrm{g} / 1$ & \\
& Preceded by a rise to & $40 \mu \mathrm{g} / 1$ &
\end{tabular}

Table III Changes in plasma CEA levels in 220 patient with and without evidence of recurrence after resection of colorectal carcinoma ${ }^{1}$

${ }^{1}$ From the data of Mackay et al (1974) who chose a plasma level of $>40 \mu \mathrm{g} / 1$ as truly abnormal. The normal range is $<20 \mu \mathrm{g} / 1$, but levels between 20 and $40 \mu \mathrm{g} / 1$ (and occasionally higher) may be $\overline{\bar{O}}$ found in patients with non-neoplastic disorders, especially if associated with regeneration.

'The recurrence was detected clinically at the same time as a rise in plasma CEA was noted.

follow-up study of 220 patients after apparently complete surgical removal of colorectal cancer, elevated 3 plasma CEA levels were detected in 36 of the 53 sub-i jects with clinical recurrences (table III). In 26 of $\frac{3}{3}$ these, the plasma levels became elevated and rose further in the period three to 18 months before the? clinical detection of recurrence or metastases (fig 1) $\frac{D}{2}$ These trends in plasma CEA in subjects with confirmed metastatic disease may allow us to conclude 0 that the other 17 subjects with values rising in excess of $40 \mu \mathrm{g} / \mathrm{l}$, although apparently clinically well, also have latent tumours (table III and fig 2). $\omega$ If so, $76 \%$ of patients, ie, 53 of 70 , will develop rise in plasma CEA, irrespective of the preoperative level, in association with recurrence or metastases, usually before the latter become clinically overt? Such changes are most likely to occur, but not exclusively, in association with hepatic metastases? 


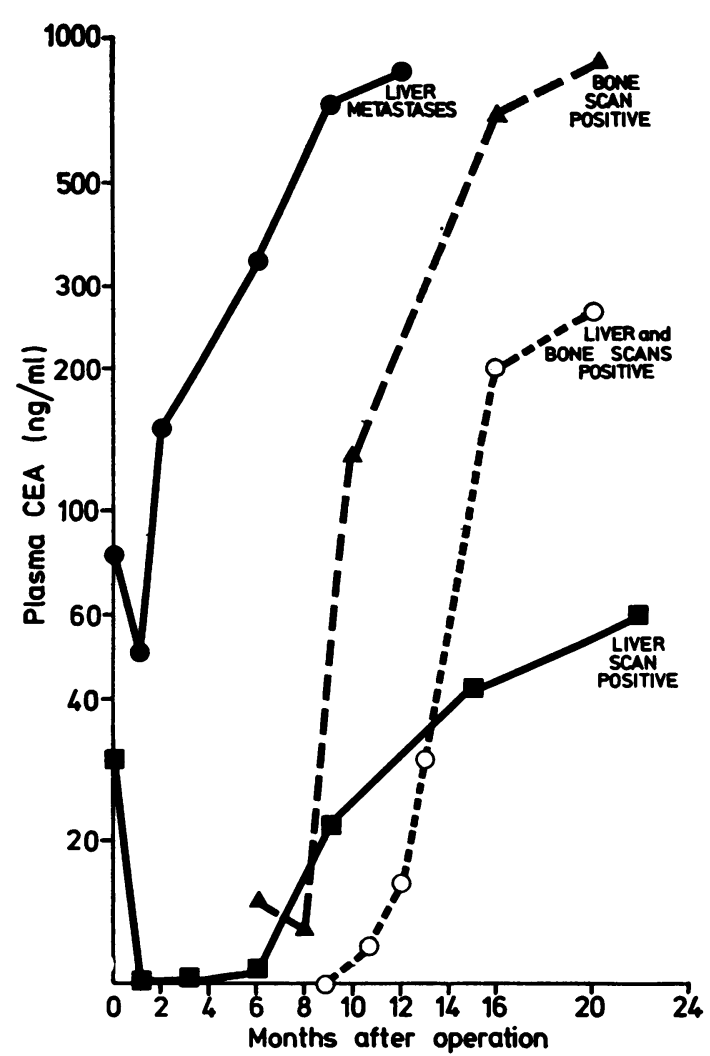

Fig 1 Serial changes in plasma CEA levels in four patients with treated carcinoma before the clinical detection of recurrence. The last recorded $C E A$ values shown coincide with the clinical detection of metastatic disease. In patient 1 ( -0$)$ only a transient decline in the CEA levels occurred postoperatively, while in patient 2 (口- ) the values returned initially to normal for a period of six months. Normal levels were recorded in patients 3 and 4 ( $\Delta \ldots . . . . \Delta ; \bigcirc \ldots . . .0)$ during the postoperative phase and then rising levels were observed. See footnote to table III for a discussion of normal and pathological levels of plasma $C E A$.

(table IV). Therefore, the serial assay of plasma CEA seems to represent a valuable addition to the armamentarium available to the clinician to detect recurrent and metastatic tumours of colorectal origin.

Vincent and Chu (1973) have presented similar data for patients with bronchial carcinoma, and we have seen similar trends in occasional patients with breast and urothelial carcinoma (Coombes et al, 1975; figs 3 and 4).

\section{Monitoring therapy}

Evidence is accumulating that serial determination of plasma CEA levels may improve the monitoring

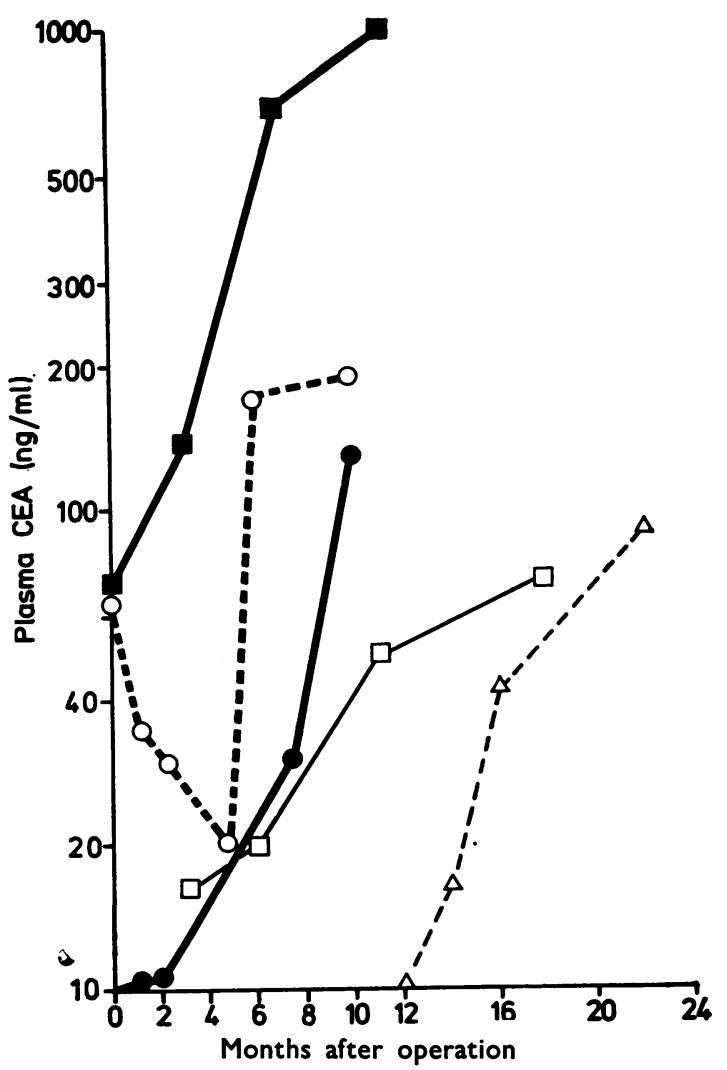

Fig 2 Serial changes in plasma CEA levels of five patients after surgical excision of carcinoma. In none was there clinical evidence of recurrent or metastatic disease. The raised preoperative level of patient 1 ( $\square$ ) failed to return to normal after operation and rose progressively. Although the levels fell after operation in patient $2(\bigcirc \ldots . . .$.$) a steady rise$ occurred thereafter. A rise is seen in patient 3 (O....... ) although the preoperative level was normal. In patients 4 and $5(\square-\square ; \triangle \ldots . . . . \triangle)$ normal CEA titres were found at the first postoperative analysis but rising leveis have since been recorded.

\begin{tabular}{llll}
\hline Metastatic Site & \multicolumn{2}{l}{ Number of Patients } \\
\cline { 2 - 4 } & \multicolumn{2}{l}{ Change in Plasma CEA } \\
\cline { 2 - 4 } & None & $\begin{array}{l}\text { Synchronous } \\
\text { Rise }^{2}\end{array}$ & $\begin{array}{l}\text { Preceded by }_{\text {Rise }^{2}} \\
\end{array}$ \\
\cline { 2 - 4 } & 7 & 7 & 17 \\
Liver & 1 & 1 & 1 \\
Lung & 7 & 5 & 5 \\
Peritoneum and pelvis & - & 1 & 1 \\
Bones & 4 & - & 2 \\
Local & 2 & - & - \\
Skin & & &
\end{tabular}

Table IV Changes in plasma CEA in relation to metastatic site in colorectal carcinoma ${ }^{1}$

${ }^{1}$ Data of Mackay et al (1974).

'To value $>40 \mu \mathrm{g} / \mathrm{l}$ 


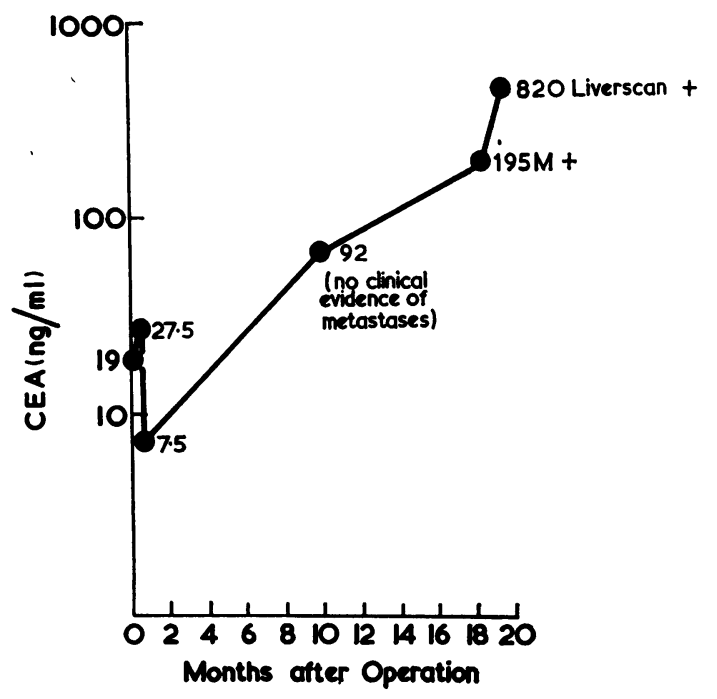

Fig 3 Female patient with mammary carcinoma observed from the time of 'curative' surgery (O). Plasma CEA values returned to normal postoperatively, but rose to pathological levels after six months and continued to rise without clinical evidence of disease until the bone scan became positive in the 18th postoperative month.

of radio- and/or chemotherapy. Objective remissions induced by various methods of treating mammary, bronchial, and occasionally colorectal carcinomas can be associated with a simultaneous decline to normal levels of plasma CEA (Vincent and Chu, 1973; Cooper and Mackay, personal communication; Skarin, Delwiche, Zamchek, Lockich, and Frei, 1974; Steward, Nixon, Zamcheck, and Aisenberg, 1974). Occasionally the clinical evidence of remission precedes the fall in plasma levels $(\mathrm{Chu}$ and Nemoto, 1973); such a delayed fall may be related to radiation- or drug-induced necrosis resulting in increased release of CEA from the tumour (Bagshawe, Rogers, Searle, and Wilson, 1973; Khoo and Mackay, 1973). In the absence of a therapeutic response rising CEA titres are generally observed, particularly with bronchial and colorectal carcinomas. Chemotherapy of these tumours may achieve steady levels of CEA for a short period of several months before there is an 'escape' with dramatically rising titres associated with the terminal phase of the disease (Cooper and Mackay, 1974).

ALPHA-FETOPROTEIN (AFP)

Alpha-fetoprotein (AFP), originally described by Abelev, Perova, Khramkova, Postnikova, and Irlin (1963), is a product of the yolk sac, fetal liver

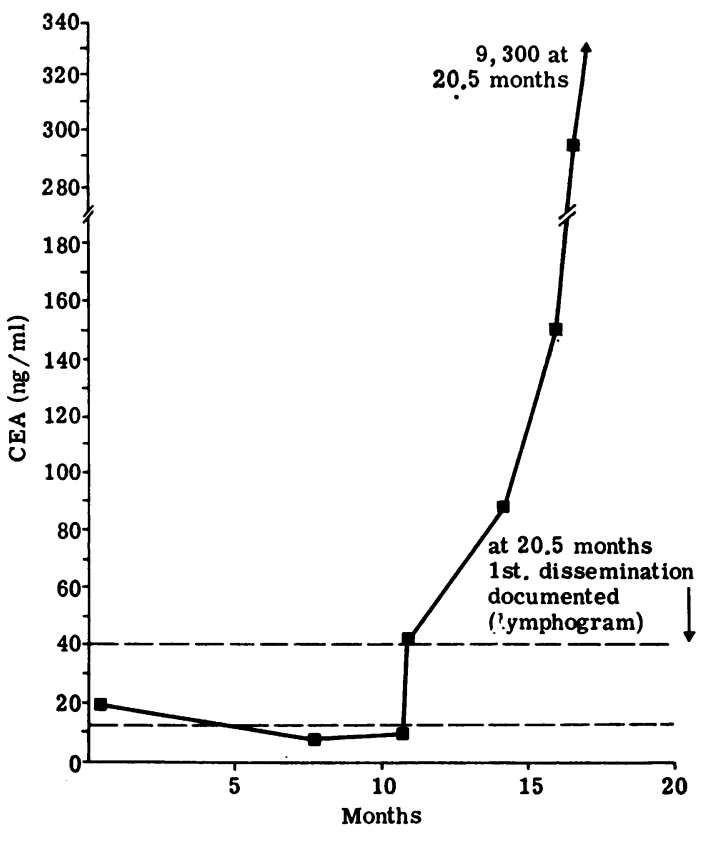

Fig 4 Male patient presented $\square$ initially with a large superficial bladder carcinoma which progressed rapidly to infiltrate the extravesical tissues. A course of radiotherapy was given. The patient died 21 months after initial examination three weeks after the first clinical evidence of extrapelvic tumour dissemination.

and gastrointestinal tract which appears in the feta blood (Gitlin, 1971). Early studies of plasma levelsô in adults suggested a specific increase in patients with primary cancer of the liver, but subsequent work with more sensitive methods has disproved. any such tumour specificity. It is now known that variety of inflammatory and regenerative conditionsmay be associated with increased blood levels (see. below).

\section{Chemistry}

Alpha-fetoprotein is an $\alpha_{1}$-globulin with a molecular weight of the order of 64000 (Nishi, 1970). Approximately $4 \%$ of the molecule is carbohydrate, with hexose, hexosamine, and sialic acid occurring in ap ratio of 2.2:1.2:0.9 (Ruoslahti et al, 1971). As with CEA, there is evidence that AFP from different sources may vary slightly in composition. While this is largely due to differing amounts of sialic acid (Purves, Van der Merwe, and Bersohn, 1970 市 Zimmerman and Madappally, 1973), two different? molecular species have recently been identified byo affinity chromatography (Smith and Kelleher, 1973).

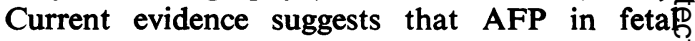


serum and the serum of hepatoma-bearing subjects are chemically identical; the total number of amino acids is the same and peptide maps are identical (Nishi, 1970; Ruoslahti, Seppälä, Pihko, and Vuopio, 1971).

Alpha-fetoprotein binds oestradiol-17 $\beta$ but not testosterone, and this may represent an important physiological function (Uriel, 1974). The possibility has also been raised that AFP may play an immunosuppressive role (Masseyeff, 1974).

\section{Sources}

The principal source of AFP during fetal life is the liver. It appears to be an intracellular product of the hepatocytes which is released into the blood stream; it is also present in high concentration in the amniotic fluid.

After birth plasma AFP levels decline progressively until the age of 2 years, after which the low level $(2.6 \pm 1.6 \mu \mathrm{g} / \mathrm{l})$ is maintained. A small rise may occur subsequently after the age of 60 years (Masseyeff, Gilli, Krebs, Bonet, and Zrihen, 1974). Consequently, as with CEA (vide supra), although the production of AFP falls significantly after birth, it is not completely suppressed.

Other sources of AFP are discussed below.

\section{Clinical applications}

The most important current clinical application of AFP assays is in obstetrics. Raised levels are found in the amniotic fluid in association with fetuses having neural tube defects or a 45/XO chromosomal constitution (Allan, Ferguson-Smith, Donald, Sweet, and Gibson, 1973; Brock, Bolton, and Monaghan, 1973; Leek, Ruoss, Kitan, and Chard, 1973; Seller, Campbell, Cottart, and Singer, 1973; Seller, 1974). In addition, raised AFP titres occur in the plasma of pregnant women with $\mathrm{Rh}$-immunization or diabetes (Seppälä and Ruoslahti, 1974), and also in conjunction with fetal distress (Seppälä and Ruoslahti, 1973). A detailed consideration of these aspects is beyond the scope of this article. New developments may be found in the proceedings of a recent conference (Masseyeff, 1974).

In oncology, the radioimmunoassay of AFP has revealed raised levels, ie, $>20 \mu \mathrm{g} / \mathrm{l}$, in a variety of different tumours, particularly hepatomas, hepatoblastomas, and malignant teratomas (table V). To date, its occurrence and role in clinical oncology has been less extensively studied than CEA and it may be that the newly available radioimmunoassay will reveal raised plasma levels in a greater variety of lesions. The molecular size of AFP allows it to pass through the 'renal glomerular basement membrane so that its detection in urine may afford a further method of monitoring neoplastic disease

\begin{tabular}{lc}
\hline Disorders & $\begin{array}{l}\text { Incidence of } \\
\text { Raised Levels }(\%)^{2}\end{array}$ \\
\hline Neoplastic & \\
Carcinoma of: & 89 \\
Liver & 22 \\
Pancreas & 25 \\
Stomach & 5 \\
Colorectum & 7 \\
Lung & 86 \\
Malignant teratoma & 31 \\
Non-neoplastic & 14 \\
Viral hepatitis & 31 \\
Alcoholic cirrhosis & 0 \\
Chronic active hepatitis & 16 \\
Extrahepatic biliary obstruction & 7 \\
Ulcerative colitis & \\
Crohn's disease & \\
\hline
\end{tabular}

Table V Incidence of raised serum AFP levels in various neoplastic and non-neoplastic disorders ${ }^{1}$

${ }^{1}$ From the data of Ruoslahti et al (1972), Purves et al (1973), Freedman (personal communication), Silver et al (1974a, b).

${ }^{2}$ That is $>20 \mu \mathrm{g} / \mathrm{l}$.

(Rosenmann, Okon, Zaitchek, Dishon, and Boss, 1974).

\section{Hepatomas and liver disease}

Almost all hepatomas produce AFP but in widely differing amounts. Purves, Manso, and Torres (1973) believe that the tumour's ability to synthesize and release AFP is set at a particular fixed rate at an early stage. The plasma level of AFP is unrelated to tumour size; not all tumour cells seem to produce AFP. Nodular and poorly differentiated tumours tend to be associated with the highest levels (Purves et al, 1973). However, in studies of liver regeneration in animals, serum AFP levels are related to the number of proliferating cells (Wepsic, Bernstein, and Sell, 1974). Extensive screening of gold miners who have a high frequency of hepatomas has failed to reveal a phase when AFP is raised in the plasma in the absence of a clinically detectable tumour (Purves et al, 1973), so that its role in early diagnosis is limited. Recent work has also shown that the plasma level is raised in non-neoplastic liver disease and hence it is not 'cancer specific' so that its differential diagnostic role also is limited (table V). From clinical and experimental studies it would appear that raised levels in non-neoplastic liver disease reflect the response of the liver to the injury rather than the severity of damage and occur in association with the regenerative phase of these disorders. With complete recovery, the levels return to normal values (Sell, Nichols, Becker, and Leffert, 1974; Silver et al, 1974). Thus, the presence of tumour may be distinguished from some forms of liver damage by the inexorable rise of AFP as shown by serial estimations.

Therapy for hepatomas is usually ineffective, but 


\begin{tabular}{|c|c|c|c|c|c|}
\hline \multirow{3}{*}{ Disorder } & \multicolumn{4}{|c|}{ Number of Patients } & \multirow{3}{*}{$\begin{array}{l}\text { Incidence of } \\
\text { Raised Levels }\end{array}$} \\
\hline & \multicolumn{4}{|c|}{ Serum AFP $(\mu g / l)$} & \\
\hline & $<20$ & $<50$ & $<100$ & $>100$ & \\
\hline Malignant teratoma & 10 & 16 & 2 & 12 & $30 / 40$ \\
\hline Seminoma & 8 & 1 & 1 & $\mathbf{0}$ & $2 / 10$ \\
\hline \multicolumn{6}{|l|}{ Malignant teratoma with } \\
\hline $\begin{array}{l}\text { (1) seminoma } \\
\text { (2) trophoblast elements }\end{array}$ & $\begin{array}{l}7 \\
3\end{array}$ & $\begin{array}{l}\mathbf{0} \\
\mathbf{0}\end{array}$ & $\begin{array}{l}\mathbf{0} \\
\mathbf{0}\end{array}$ & $\begin{array}{l}0 \\
0\end{array}$ & $\begin{array}{l}0 / 7 \\
0 / 3\end{array}$ \\
\hline 'Successfully' treated malignant teratoma & 7 & 0 & $\mathbf{0}$ & 0 & $0 / 7$ \\
\hline
\end{tabular}

Table VI Gonadal tumours and serum AFP levels

\begin{tabular}{llll}
\hline Stage & Incidence of Raised Levels & Differentiation & Incidence of Raised Levels \\
\hline I & $5 / 5$ & Differentiated & $1 / 1$ \\
II & $4 / 4$ & Intermediate & $15 / 20$ \\
III & $6 / 7$ & Anaplastic & $14 / 19$ \\
IV & $16 / 24$ & Combined teratoma and seminoma & $0 / 10$ \\
\hline
\end{tabular}

Table VII Serum AFP levels in relation to tumour stage and differentiation of malignant gonadal teratoma

in those few cases successfully treated by partial hepatectomy plasma AFP values return to baseline levels (McIntire, Vogel, Princler, and Patel, 1972).

\section{Malignant teratomas}

In man and animals the rare yolk sac tumours produce raised AFP levels in the plasma (Ballas, 1972); benign teratomas, in contrast, are associated with normal levels (Hooghe, Zeicher, Sobis, and Vandeputte, 1974). Our own preliminary studies of the occurrence of AFP in the plasma of patients with gonadal malignant teratomas are shown in table VI. Raised levels appear to be independent of tumour differentiation and to be less stage-dependent than CEA levels (table VII). To date, none of the combined tumours in our series ${ }^{1}$ has been associated with raised levels although this is known to occur (Braunstein, McIntire, and Waldmann, 1973).

Successful surgical therapy results in a return of the AFP levels to the normal range (table VI), and preliminary data suggest that sequential AFP levels may be useful as a guide to the efficacy of chemoand/or radiotherapy. The incorporation of measurements of other tumour index substance, eg, human chorionic gonadotrophin, may be highly beneficial as different populations of tumour cells producing different products can show differential therapeutic responses (Braunstein et al, 1973).

Serial AFP assays may help in the earlier detection of recurrence or metastases, although recurrence can occur without a concomitant rise in AFP levels

1That is mixed tumours containing elements of teratoma and seminoma.
(Esterhay, Shapiro, Sutherland, McIntire, and Wiernik, 1973).

\section{Other tumours}

A variety of other tumours may be associated we raised AFP levels, particularly in the presence hepatic metastases. A recent study of CEA and AFP levels in the blood of patients with gastrico carcinomas, has shown that some tumours produceo one or other antigen, and a few produce both, so을 that determining both can increase the detection rate $\overrightarrow{0}$ (Ravry, McIntire, Moertel, Waldmann, Schutt, and 3 Go, 1974).

\section{Cancer-specific Antigens}

This group of materials is still regarded as having a high degree of specificity for tumours. They areo possibly of greater biological importance than the 3 tumour-associated macromolecules because of their ${ }_{0}$ influence upon the tumour-bearing subject's immune system. Only one of these materials has been studiedo chemically in any significant detail, namely, the cancer basic protein. The remainder have been $N$ identified immunologically and are now the subject $N$ of intensive chemical investigation.

\section{CANCER BASIC PROTEIN}

In an attempt to develop a reliable quantitative method of measuring cell-mediated immune reactions ${ }_{\infty}^{\Phi}$ in vitro Field and Caspary (1970) devised the macro-: phage electrophoretic mobility (MEM) test. They noted that subjects with malignant tumours exhibited $\underset{\mathbb{D}}{\stackrel{D}{*}}$ lymphocyte sensitization to a basic protein of myelin, $\frac{\stackrel{?}{\mathbb{D}}}{\stackrel{\circ}{\circ}}$ 
encephalitogenic factor (EF). Further studies revealed that a basic protein, present in human tumours, the so-called cancer basic protein, could also produce this phenomenon; it is chemically related to EF but is not identical with it.

\section{Chemistry}

Current studies indicate that cancer basic protein (CaBP) is a 'cancer-specific' antigen which is common to all human malignant neoplasms (Carnegie, Caspary, and Field, 1973; Dickinson, Caspary, and Field, 1973). It has basic properties and a molecular weight of the order of 16000 (Dickinson and Caspary, 1973). After tryptic digestion, an active fragment is released composed solely of amino acids, less than 4000 daltons in molecular weight and containing one tryptophan residue essential for activity in the MEM test (Dickinson and Caspary, 1973).

This tumour antigen is considered to reside on the cell surface and approximately $10^{4}$ molecules of antigenically active material are present per cell (Dickinson et al, 1973). It is thought to be absent from normal cells which, however, contain a related material (Dickinson, McDermott, Smith, and Caspary, 1974).

\section{Sources}

Cancer basic protein has been extracted from, or detected in, all malignant human tumours studied to date. They include a wide variety of structurally and histogenetically different neoplasms including those of mesenchymal origin. It has not been detected in normal adult tissues, benign tumours, hyperplastic and fresh fetal tissues, but can appear in fetal tissues after five and a half hours in tissue culture (Field, Hughes, and Caspary, 1973b).

\section{Clinical applications}

The MEM test and its clinical significance have now been assessed by several workers (Goldstone, Kerr, and Irune, 1973; Pritchard, Moore, Sutherland, and Joslin, 1973a, b) and some technical improvements resulting in increased sensitivity have been made
(Pritchard et al, 1973b). Some of the most recently published data recorded by Field and his associates (1973a) are shown in table VIII. All but one of the histologically proven malignant tumours gave a positive result independent of tumour stage or differentiation, even when they were lesions in situ. Positive results have also been obtained before the development of overt tumours. Once the test is positive, it remains so, even after surgery, in contrast to tuberculosis where continuing disease activity is required for persistence of sensitivity reactions.

Of 319 patients with suspected cancer, histological proof of carcinoma was obtained in 168 out of 255 with positive results; in the remainder the result of the pathological study is awaited to confirm or refute the diagnosis. Of 113 patients with prostatic disease, $\mathbf{3 0}$ gave positive results and all but three of these were found to have carcinoma. However, six patients diagnosed as having carcinoma histologically gave normal results.

Hence, not all their tumour cases gave positive results. It is known also that patients with lymphomas show a low positivity rate and that all cases of lymphatic leukaemia are negative. With further experience of regenerative and inflammatory lesions and pre-neoplastic states, a 'grey' zone is emerging with occasional positive results. A list of conditions, including neurological disease, in which the MEM test may give false positive results, has been compiled (Field et al, 1973a) to which peripheral vascular disease must now be added (Bagshawe, personal communication).

An alternative immunodiagnostic procedure employing CaBP as the test antigen has recently been developed by Cercek, Cercek, and Franklin (1974). It depends upon changes in the structural organization of cytoplasmic matrix which are induced by $\mathrm{CaBP}$ in lymphocytes of cancer-bearing subjects but not in those from healthy donors. Present evidence has shown a clear separation of malignant cases from a non-malignant group which included subjects with preneoplastic and regenerative conditions and pregnancy. This test system offers a practicable

Disorder

\begin{tabular}{ll} 
Number of Patients & \\
\hline $\begin{array}{l}\text { Incidence of Positive } \\
\text { Results }\end{array}$ & $\begin{array}{l}\text { Histological Proof of } \\
\text { Cancer Obtained } \\
\text { Subsequently }\end{array}$ \\
\hline $295 / 296$ & 168 \\
$255 / 319$ & $27^{2}$ \\
$30 / 113$ &
\end{tabular}

Patients in whom

Patients admitted for TUR of prostate

27

Table VIII Incidence of positive tests obtained by the macrophage electrophoretic mobility $(M E M)$ test $^{1}$

${ }^{1}$ From the data of Field, Caspary, and Smith (1973).

'A further six patients who gave negative MEM results were diagnosed as having carcinoma histologically. 
alternative to the MEM test and avoids the difficulties of handling macrophage suspensions.

The various positive results obtained in the MEM test in some inflammatory and other non-neoplastic diseases indicate that $\mathrm{CaBP}$ can no longer be regarded as 'cancer-specific'. Nonetheless, the use of $\mathrm{CaBP}$ in clinical oncology still appears to be a most promising development to facilitate the earlier detection of tumours, though it will have no role in thefollow-up phases because it persists after "curative surgery'.

ORGAN OR TYPE-SPECIFIC ANTIGENS

Many human tumours, including colonic, ovarian, bronchial, mammary, and urothelial carcinoma, neuroblastoma, melanoma, lymphoma, and sarcoma have now been shown to possess organ or typespecific antigens. Their existence has been detected most often by lymphocyte cytotoxicity methods in vitro (Hellstrom and Hellstrom, 1974) based on the fact that lymphocytes from a tumour-bearing subject will exert toxic effects on the cells of that patient's tumour and those of tumours of the same organ from other patients but not on cells from tumours arising in other tissues, eg, reactions will occur between lymphocytes of a breast cancer subject and all breast tumour cells but not against colorectal carcinoma cells or those from a sarcoma or melanoma.

Evidence from experimentally induced and human tumours suggests that these antigens are shed by the tumour cells into the blood where they may exist free or as antigen-antibody complexes; the latter may account for the inhibition of lymphocyte cytotoxicity in vitro seen with advancing disease (so-called 'blocking factors') (Currie, 1973; Embleton, 1973; Baldwin, Embleton, Price, and Vose, 1974). What effect this phenomenon has upon the progression of the disease in vivo remains to be clarified.

At present, therefore, these types of antigens are regarded as being tumour-specific because they have not so far been detected in non-neoplastic tissues, and as organ specific with respect to the origin of the tumour. Recent work has shown that experimental tumours, in addition to possessing tumour-specific transplantation (rejection) antigens, also possess embryonic antigens at the cell surface which are immunogenic and which exhibit organ specificity (Baldwin et al, 1974). Consequently, it is important now to ascertain if the organ-specific antigens of human tumours are also embryonic in type like CEA and AFP although differing from the latter in their immunogenic action on the host. The future possibility of isolating such organ specific antigens in pure form and developing sensitive methods for detecting their presence in body fluids or their effects upon the immune system could have far- reaching implications in the clinical managements and detection of neoplasia.

\section{Summary}

The concept of tumour-specific antigens is constantlye undergoing reappraisal with the development of more sensitive methods for their detection. This hasD resulted in the finding that the many 'new' antigens, produced by human tumours or materials immuno-s logically closely related to them are also present $\overrightarrow{0}$ in non-neoplastic tissues, albeit in small amounts However, other antigens still appear to exist almosfu entirely in or on tumour cells so that the antigen of human tumours may be subdivided into eithe tumour-associated macromolecules or tumour $-\overrightarrow{1}$ specific antigens.

The elucidation of the chemical nature of the tumour-specific antigens may result in importan⿸尸 advances in cancer diagnosis and therapy. As many? are organ specific, it should be possible to evolve test systems which will enable tumours to be diagnosed and located before they become apparen clinically.

On the other hand the tumour-associated macromolecules, of which the oncofetal antigens are the principal examples, are found in elevated amougts in some non-neoplastic disorders. It is now cleap that serial estimation of the levels of these mactos molecules is of considerably more diagnostic value than single random measurements. Current work id establishing their value in the detection of recurren and metastatic tumours before they become apparen by other methods, which is probably their mos? important role, and also their value as aids to monitor therapeutic efficacy.

The future use of both types of antigen may unfold: a new era in cancer detection and therapy but many basic chemical and immunological studies are needed before their clinical use can be fully defined.

\section{References}

Abelev, G. I. (1974). $\alpha$-Fetoprotein as a marker of embryo-specific differentiations in normal and tumor tissues. Transplant Rev $20,3$.

Abelev, G. I., Perova, S. D., Khramkova, N. I., Postnikova, Z. A and Irlin, I. S. (1963). Production of embryonal a-globulin b) transplantable mouse hepatomas. Transplantation, 1, 174.

Allan, L. D., Ferguson-Smith, M. A., Donald, I., Sweet, E. M., an氏U Gibson, A. A. M. (1973). Amniotic-fluid alpha-fetoprotein if the antenatal diagnosis of spina bifida. Lancet, $2,522$.

Bagshawe, K. D., Rogers, G. T., Searle, F., and Wilson, H. (1973) Blood carcinoembryonic antigen, Regan isoenzyme, and humair chorionic gonadotrophin in primary mediastinal carcinome? Lancet, 1, 210.

Baldwin, R. W., Embleton, M. J., Price, M. R., and Vose, B. Mo (1974). Embryonic antigen expression on experimental rat tumours. Transplant. Rev., 20, 77.

Ballas, M. (1972). Yolk sac carcinoma of the ovary with alphā foetoprotein in serum and ascitic fluid demonstrated bF immunoosmophoresis. Amer. J. clin. Path., 57, 511. 
Banjo, C., Shuster, J., and Gold, P. (1974). Intermolecular heterogeneity of the carcinoembryonic antigen. Cancer Res., 34, 2114 .

Banwo, O., Versey, J., and Hobbs, J. R. (1974). New oncofetal antigen for human pancreas. Lancet, 1, 643 .

Björklund, B., Björklund, V., Wiklund, B., Lundström, R., Ekdahl, P. H., Hagbard, L., Kaijser, K., Eklund, G., and Lüning, B. (1973). A human tissue polypeptide related to cancer and placenta. I. Preparation and properties. II. Assay technique. III. Clinical studies of 1,483 individuals with cancer and other conditions. In Immunological Techniques for Detection of Cancer: Proceedings of the Folksam Symposium, 1972, edited by B. Björklund, pp. 183-187. Bonniers, Stockholm.

Braunstein, G. D., McIntire, K. R., and Waldmann, T. A. (1973). Discordance of human chorionic gonadotrophin and alphafetoprotein in testicular teratocarcinomas. Cancer (Philad.), 31, 1065.

Brock, D. J. H., Bolton, A. E., and Monaghan, J. M. (1973). Prenatal diagnosis of anencephaly through maternal serum-alphafoetoprotein measurement. Lancet, 2, 923.

Carnegie, P. R., Caspary, E. A., and Field, E. J. (1973). Isolation of an 'antigen' from malignant tumours. Brit. J. Cancer, 28, Suppl. 1, 219.

Cercek, L., Cercek, B., and Franklin, C. I. V. (1974). Biophysical differentiation between lymphocytes from healthy donors, patients with malignant diseases and other disorders. Brit. J. Cancer, 29, 345.

Chu, T. M. (1974). Quoted in Neville and Laurence (1974).

Chu, T. M., Bhargava, A. K., and Harvey, S. R. (1974). Structure studies of the glycoproteins associated with carcinoembryonic antigen (CEA) activity. Fed. Proc., 33, 1562.

Chu, T. M., and Nemoto, T. (1973). Evaluation of carcinoembryonic antigen in human mammary carcinoma. J. nat. Cancer Inst., $51,1119$.

Coligan, J. E., Henkart, P. A., Todd, C. W., and Terry, W. D. (1973). Heterogeneity of the carcinoembryonic antigen. Immunochemistry, 10, 591.

Coombes, G. B., Hall, R. R., and Neville, A. M. (1975). Urinary carcinoembryonic antigen (CEA)-like molecules and urothelial malignancy: a clinical appraisal. Brit. J. Cancer, 31, 135.

Currie, G. (1973). The role of circulating antigen as an inhibitor of tumour immunity in man. Brit. J. Cancer, 28, Suppl. 1, 153.

Denk, H., Tappeiner, G., Eckerstorfer, R., and Holzner, J. H. (1972). Carcinoembryonic antigen (CEA) in gastrointestinal and extragastrointestinal tumors and its relationship to tumor-cell differentiation. Int. J. Cancer, 10, 262.

Dickinson, J. P., and Caspry, E. A. (1973). The chemical nature of cancer basic protein. Brit. J. Cancer, 28, Suppl. 1, 224.

Dickinson, J. P., Caspary, E. A., and Field, E. J. (1973). A common tumour specific antigen. I. Restriction in vivo to malignant neoplastic tissue. Brit. J. Cancer, 27, 99.

Dickinson, J. P., McDermott, J. R., Smith, J. K., and Caspary, E. A. (1974). A common tumour specific antigen. II. Further characterization of the whole antigen and of a cross-reacting antigen of normal tissues. Brit. J. Cancer, 29, 425.

Embleton, M. J. (1973). Significance of tumour associated antigens on human colonic carcinomata. Brit. J. Cancer, 28, Suppl. $1,142$.

Esterhay, R. J., Shapiro, H. M., Sutherland, J. C., McIntire, K. R. and Wiernik, P. H. (1973). Serum alpha fetoprotein concentration and tumor growth dissociation in a patient with ovarian teratocarcinoma. Cancer (Philad.), 31, 835.

Field, E. J., and Caspary, E. A. (1970). Lymphocyte sensitisation: an in vitro test for cancer? Lancet, $2,1337$.

Field, E. J., Caspary, E. A., and Smith, K. S. (1973a). Macrophage electrophoretic mobility (MEM) test in cancer: A critical evaluation. Brit. J. Cancer, 28, Suppl. 1, 208.

Field, E. J., Hughes, D., and Caspary, E. A. (1973b). Rapid development of a cancer-like antigen in normal tissue in vitro. Brit. J. Cancer, 27, 427.

Fleisher, M., Oettgen, H. F., Breed, C. N., Robbins, G. F., Pinsky, C. M., and Schwartz, M. K. (1974). CEA-like material in fluid from benign cysts of the breast. Clin. Chem., 20, 41 .

Gitlin, D. (1971). Sites of alpha-fetoprotein synthesis. (Letter) New Engl. J. Med., 285, 1436.

Gold, P., and Freedman, S. O. (1965). Specific carcinoembryonic antigens of the human digestive system. J. exp. Med., 122, 467.

Gold, P., Krupey, J., and Ansari, H. (1970). Position of the carcinoembryonic antigen of the human digestive system in ultrastructure of tumor cell surface. J. nat. Cancer Inst., 45, 219.
Goldstone, A. H., Kerr, L., and Irvine, W. J. (1973). The macrophage electrophoretic migration test in cancer. Clin. exp. Immunol., $14,469$.

Häkkinen, I. P. T. (1974). FSA-foetal sulphoglycoprotein antigen associated with gastric cancer. Transplant Rev., 20, 61 .

Hellström, K. E., and Hellström, I. (1974). Lymphocyte mediated cytotoxicity and blocking serum activity to tumor antigens. Advanc. Immunol., 18, 209.

Hooghe, E., Zeicher, M., Sobis, H., and Vandeputte, M. (1974). In Alpha-Feto-Protein: Proceedings of the International Conference, edited by R. Masseyeff, pp. 271-274. Inserm, Paris.

Khoo, S. K., and Mackay, E. V. (1973). Carcinoembryonic antigen in cancer of the female reproductive system: sequential levels and effects of treatment. Aust. N.Z. J. Obstet. Gynaec., 13, 1.

Khoo, S. K., Warner, N. L., Lie, J. T., and Mackay, I. R. (1973) Carcinoembryonic antigenic activity of tissue extracts: a quantitative study of malignant and benign neoplasms, cirrhotic liver, normal adult and fetal organs. Int.J. Cancer, 11, 681.

von Kleist, S., and Burtin, P. (1969). Localisation cellulaire d'un antigène embryonnaire de tumeurs coliques humaines. Int. $J$. Cancer, 4, 874.

Krupey, J., Gold, P., and Freedman, S. O. (1968) Physiochemica studies of the carcimoembryonic antigens of the human digestive system. Jr Exp. Med. 128, 387.

Krupey, J., Wilson, T., Freedman, S. O., and Gold, P. (1972). The preparation of purified carcinoembryonic antigen of the human digestive system from large quantities of tumor tissue. Immunochemistry, 9, 617.

Laurence, D. J. R., and Neville, A. M. (1972). Foetal antigens and their role in the diagnosis and clinical management of human neoplasms: a review. Brit. J. Cancer, 26, 335.

Laurence, D. J. R., Stevens, U., Bettelheim, R., Darcy, D., Leese, C. Turberville, C., Alexander, P., Johns, E. W., and Neville, A. M. (1972). The role of plasma carcinoembryonic antigen in diagnosis of gastrointestinal, mammary and bronchial carcinoma. Brit. med. J., 3, 605.

Leek, A. R., Ruoss, C. F., Kitau, M. J., and Chard, T. (1973). Raised a-fetoprotein in maternal serum with anencephalic pregnancy. Lancet, 2, 385.

Mach, J. P., Jaeger, P., Bertholet, M. M., Ruegsegger, O. H., Loosli, R. M., and Pettavel, J. (1974). Detection of recurrence of large bowel carcinoma by radioimmunoassay of circulating carcinoembryonic antigen (CEA). Lancet, 2, 536.

McIntire, K. R., Vogel, C. L., Princler, G. L., and Patel, I. R. (1972). Serum a-fetoprotein as a biochemical marker for hepatocellular carcinoma. Cancer Res., 32, 1941.

Mackay, A. M., Patel, S., Carter, S., Stevens, U., Laurence, D. J. R., Cooper, E. H., and Neville, A. M. (1974). The role of serial plasma CEA assays in the detection of recurrent and metastatic colorectal carcinomas. Brit. med. J., 4, 382.

Masseyeff, R., Ed. (1974). Alpha-Feto-Protein: Proceedings of the International Conference. Inserm, Paris.

Masseyeff, R., Gilli, J., Krebs, B., Bonet, C., and Zrihen, H. (1974). In Alpha-Feto-Protein: Proceedings of the International Conference, edited by R. Masseyeff, pp. 313-322. Inserum, Paris.

Nery, R., Barsoum, A. L., Bullman, H., and Neville, A. M. (1974a). Carcinoembryonic antigen-like substances from human urothelial carcinomas. Isolation of components from pathological urine and comparison with colorectal carcinoma antigens. Biochem. J., 139, 431.

Nery, R., James, R., Barsoum, A. L., and Bullman, H. (1974b). Isolation and partial characterization of macromolecular urinary aggregates containing carcinoembryonic antigen-like activity. Brit. J. Cancer, 29, 413.

Neville, A. M., and Laurence, D. J. R. (1974). Report of the workshop of the carcinoembryonic antigen (CEA): the present position and proposals for future investigation. Int. J. Cancer, 14, 1.

Neville, A. M., Nery, R., Hall, R. R., Turberville, C., and Laurence, D. J. R. (1973). Aspects of the structure and clinical role of the carcino-embryonic antigen (CEA) and related macromolecules with particular reference to urothelial carcinoma. Brit. J. Cancer, 28, Suppl. 1, 198.

Newman, E. S., Petras, S. E., Hamilton, J. G., Hager, H. J., and Hansen, H. J. (1972). Demonstration of two tumor associated antigens in human colonic adenocarcinoma. (Abstr,) Fed. Proc., 31, 639.

Nishi, S. (1970). Isolation and characterisation of a human fetal a-globulin from the sera of fetuses and a hepatoma patient. Cancer Res., 30, 2507. 
Pritchard, J. A. V., Moore, J. L., Sutherland, W. H., and Joslin, C. A. F. (1973a). Technical aspects of the macrophage electrophoretic mobility (MEM) test for malignant disease. Brit. J. Cancer, 28, Suppl. 1, 229.

Pritchard, J. A. V., Moore, J. L., Sutherland, W. H., and Joslin, C. A. F. (1973b). Evaluation and development of the macrophage electrophoretic mobility (MEM) test for malignant disease. Brit. J. Cancer, 27, 1.

Purves, L. R., Manso, C., and Torres, F. O. (1973). Serum a-fetoprotein levels in people susceptible to primary liver cancer in southern Africa. Gann Monogr., 14, 51.

Purves, L. R., Van der Merwe, E., and Bersohn, I. (1970). Serum alpha-feto-protein. $V$. The bulk preparation and some properties of alpha-feto-protein obtained from patients with primary cancer of the liver. S. Afr. J. Med., 44, 1264.

Ravry, M., McIntire, K. R., Moertel, C. G., Waldmann, T. A. Schutt, A. J., and Go, V. L. W. (1974). Carcinoembryonic antigen and alpha-fetoprotein in the diagnosis of gastric and colonic cancer: a comparative clinical evaluation. J. nat. Cancer Inst., 52, 1019.

Rosenmann, E., Okon, E., Zaitchek, G., Dishon, T., and Boss, J. H. (1974). In Alpha-Feto-Protein: Proceedings of the International Conference, edited by R. Masseyeff, pp. 345-352. Inserm, Paris.

Ruoslahti, E., Pihko, H., and Seppälä, M. (1974). Alpha-fetoprotein : immunochemical purification and chemical properties. Expression in normal state and in malignant and non-malignant liver disease. Transplant. Rev., $20,38$.

Ruoslahti, E., Seppälä, M., Pihko, H., and Vuopio, P. (1971). Studies of carcino-fetal proteins. II. Biochemical comparison of a-fetoprotein from human fetuses and patients with hepatocellular cancer. Int. J. Cancer, 8, 283.

Ruoslahti, E., Seppälä, M., Vuopio, P., Saksela, E., and Peltokallio, P. (1972). Radioimmunoassay of alpha-fetoprotein in primary and secondary cancer of the liver. J. nat. Cancer. Inst., 49, 623.

Sell, S., Nichols, M., Becker, F. F., and Leffert, H. L. (1974). Hepatocyte proliferation and $a_{1}$-fetoprotein in pregnant, neonata and partially hepatectomized rats. Cancer Res., 34, 865.

Seller, M. J. (1974). In Alpha-Feto-Protein: Proceedings of the International Conference, edited by R. Masseyeff, pp. 383-386. Inserm, Paris.

Seller, M. J., Campbell, S., Coltart, T. M., and Singer, J. D. (1973). Early termination of anencephalic pregnancy after detection by raised alpha-fetoprotein levels. Lancet, 2,73 .

Seppälä, M., and Ruoslahti, E. (1973). Alpha fetoprotein in maternal serum: a new marker for detection of fetal distress and intrauterine death. Amer. J. Obstet. Gynec., 115, 48.

Seppälä, M., and Ruoslahti, E. (1974). In Alpha-Feto-Protein: Proceedings of the International Conference, edited by $\mathbf{R}$ Masseyeff, pp. 387-392. Inserm, Paris.

Silver, H. K. B., Deneault, J., Gold, P., Thompson, W. G., Shuster, J., and Freedman, S. O. (1974a). The detection of $a_{1}$-fetoprotein in patients with viral hepatitis. Cancer Res., 34, 244.

Silver, H. K. B., Gold, P., Shuster, J., Javitt, N. B., Freedman, S. O., and Finlayson, N. D. C. (1974b). Alpha-fetoprotein in chronic liver disease. New Engl. J. Med., 291, 506.
Skarin, A. T., Delwiche, R., Zamcheck, N., Lokich, J. J., and Frei, E., II (1974). Carcinoembryonic antigen: clinical correlation with chemotherapy for metastatic gastrointestinal cancer. Cancer? (Philad.), 33, 1239.

Smith, C. J., and Kelleher, P. C. (1973). $a_{1}$-Fetoprotein: Separation: of two molecular variants by affinity chromatography with concanavalin A-agarose. Biochim. biophys. Acta (Amst.) + 317, 231.

Sorokin, J. J., Sugarbaker, P. H., Zamcheck, N., Pisick, M., Kupchik H.Z., and Moore, F. D. (1974). Serial carcinoembryonic antigen assays: use in detection of cancer recurrence. J. Amer. med. Ass., $228,49$.

Steward, A. M., Nixon, D., Zamcheck, N., and Aisenberg, A. (1974). Carcinoembryonic antigen in breast cancer patients: serumb levels and disease progress. Cancer (Philad.), 33, 1246.

Stonehill, E. H., and Bendich, A. (1970). Retrogenetic expression $\overrightarrow{0}$ the reappearance of embryonal antigens in cancer cells.Nature (Lond.), 228, 370.

Terry, W. D., Henkart, P. A., Coligan, J. E., and Todd, C. W. (1972) Structural studies of the major glycoprotein in preparations with carcinoembryonic antigen activity. J. exp. Med., 136, 200응

Terry, W. D., Henkart, P. A., Coligan, J. E., and Todd, C. W. (1974) Carcinoembryonic antigen: characterisation and clinical applications. Transplant. Rev., 20, 100.

Thomas, P., Westwood, J. H., and Foster, A. B. (1974). The role of disulphide bridges in the structure and immunological activity of the carcinoembryonic antigen. Biochem. Soc. Trans., 2, 1248.

Thomson, D. M. P., Krupey, J., Freedman, S. O., and Gold, P! (1969). The radioimmunoassay of circulating carcinoembryonic antigen of the human digestive system. Proc. Nat. Acad. Sci. (Wash.), 64, 161.

Turberville, C., Darcy, D. A., Laurence, D. J. R., Johns, E. W., and Neville, A. M. (1973). Studies on carcinoembryonic antigen? (CEA) and a related glycoprotein, CCEA-2: preparation anc chemical characterisation. Immunochemistry, 10, 841.

Uriel, J. (1974). In Alpha-Feto-Protein: Proceedings of the International Conference, edited by $R$. Masseyeff, pp. 393-402.0 Inserm, Paris.

Vandevoorde, J. P., Newman, E. S., Fresolone, J., MacDonald, R.P. . V and Hansen, H. J. (1973). Study of carcinoembryonic antr 'like' activity in human semen and in urine from patients bladder carcinoma. (Abstr.) Fed. Proc., 32, 1007.

Vincent, R. G., and Chu, T. M. (1973). Carcinoembryonic antigen in patients with carcinoma of the lung. J. thorac. cardiovasc. Surg. 66, 320.

Wepsic, H. T., Bernstein, P., and Sell, S. (1974). In Alpha-Feto-尺 Protein: Proceedings of the International Conference, edited by R. Masseyeff, pp. 405-420. Inserm, Paris.

Westwood, J. H., Bessell, E. M., Bukhari, M. A., Thomas, P., and Walker, J. M. (1974a). Studies on the structure of the carcinoembryonic antigen. I. Some deductions on the basis of chemica? degradation. Immunochemistry, 11, 811.

Westwood, J. H., Thomas, P., and Foster, A. B. (1974b). The treat ment of carcinoembryonic antigen with sodium metaperio date. Biochem. Soc. Trans., 2, 1250.

Zimmerman, E. F., and Madappally, M. M. (1973). Sialyltransferase $\bar{C}$ regulation of $a$-foetoprotein microheterogeneity during development. Biochem. J., 134, 807. 